\title{
Comparison of methods for DE-CMR infarct size quantification - reproducibility among three core labs
}

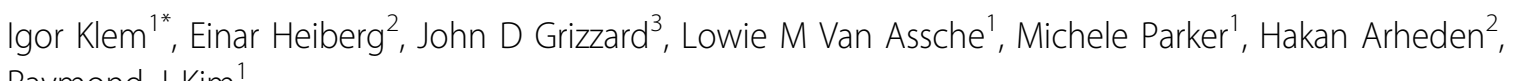
Raymond J Kim ${ }^{1}$

From 16th Annual SCMR Scientific Sessions

San Francisco, CA, USA. 31 January - 3 February 2013

\section{Background}

Infarct size measurements with delayed-enhancement cardiovascular magnetic resonance (DE-CMR) are being used as surrogate endpoints in acute myocardial infarction (AMI) trials comparing therapeutic strategies. Semiautomated techniques using signal intensity thresholding are thought to be more reproducible than manual planimetry to define AMI borders. For both methods, endo-/ epicardial borders are determined by manual planimetry, which was not considered in prior reproducibility studies. Visual scoring of AMI size based on a standard 17-segment, 5-point score is faster and does not require planimetry of endo-/epicardial borders. We compared the reproducibility of visual scoring, manual planimetry and semiautomated techniques.

\section{Methods}

Thirty patients with first AMI (58+/-11 years, $80 \%$ male), who underwent DE-CMR within 7 days after first elevated troponin test were enrolled. All scans were evaluated independently at each participating CMR core lab with at least three months temporal separation between analyses in the following manner: A) manual planimetry of the endo-/epicardial contours and infarct borders (MP), B) manual planimetry of endo-/epicardial contours, AMI size determined using a semiautomated technique with voxel weighting based on signal intensity, without user input (AUTO), C) same as B with user correction for no-reflow, artifact, etc. (AUTOcorrected), and D) visual scoring using a 17-segment, 5-point score (VISUAL). This comparison is based on a total of 30 measurements by three core-labs in four different manners for a total of 360 AMI size measurements.

Interobserver reproducibility was assessed using a) standard error of difference from mean (SED), and b) 1-intraclass-correlation coefficient (ICC). A SED $<3$ and $1-\mathrm{ICC}<0.10$ are considered excellent reproducibility.

\section{Results}

The mean AMI sizes by MP as \%LV were similar among 3 readers $(20.5 \pm 11.02 \%, 20.02 \pm 11.59 \%$, and 18.73 $\pm 11.09 \%$; $=\mathrm{NS}$ ). The results for the reproducibility are shown in the Table. The interobserver agreement between three readers for AMI size was excellent for all three techniques. Even with the use of a semiautomated technique without any user correction of AMI borders, there is variability in AMI size (AUTO: SED 2.90, 1-ICC 0.088 ), which is due to variability of the endo-/epicardial

Table 1 Measures of Reproducibility

\begin{tabular}{ccccc}
\hline & Manual Planimetry & AUTO & AUTOcorrected & VISUAL \\
\hline Standard error of difference (SED) & 2.79 & 2.90 & 2.16 & 2.40 \\
\hline 1-ICC & 0.061 & 0.088 & 0.043 & 0.099 \\
\hline
\end{tabular}

${ }^{1}$ Medicine, Duke University, Durham, NC, USA

Full list of author information is available at the end of the article

(C) 2013 Klem et al; licensee BioMed Central Ltd. This is an Open Access article distributed under the terms of the Creative Commons 
border planimetry. Variability of AUTO is improved after manual user correction of AMI borders (AUTOcorrected: SED 2.16, 1-ICC 0.043). Manual planimetry of endo-/epicardial and AMI borders as well as rapid visual scoring AMI size have a similar reproducibility to semiautomated techniques.

\section{Conclusions}

The interobserver reproducibility of manual planimtery, semiautomated techniques, and visual scoring for AMI size quantification is similar and excellent. Variability of semiautomated techniques is due to planimetry of endo-/ epicardial borders.

\section{Funding}

NIH.

\section{Author details}

${ }^{1}$ Medicine, Duke University, Durham, NC, USA. ${ }^{2}$ Cardiac MR group,

Department of Clinical Physiology, Lund University Hospital, Lund, Sweden.

${ }^{3}$ Radiology, Virginia Commonwealth University, Richmond, VA, USA.

Published: 30 January 2013

doi:10.1186/1532-429X-15-S1-P180

Cite this article as: Klem et al:: Comparison of methods for DE-CMR

infarct size quantification - reproducibility among three core labs.

Journal of Cardiovascular Magnetic Resonance 2013 15(Suppl 1):P180.

Submit your next manuscript to BioMed Central and take full advantage of:

- Convenient online submission

- Thorough peer review

- No space constraints or color figure charges

- Immediate publication on acceptance

- Inclusion in PubMed, CAS, Scopus and Google Scholar

- Research which is freely available for redistribution

Submit your manuscript at www.biomedcentral.com/submit
C Biomed Central 